Painter, H. A. (1954). J. gen. Microbiol. 10, 177-190.

\title{
Factors affecting the Growth of some Fungi associated with Sewage Purification
}

\author{
By H. A. PAINTER \\ Water Pollution Research Laboratory, Langley Road, Watford, Hertfordshire
}

SUMMARY: Various aspects of the nutrition of four fungi which commonly inhabit percolating filters treating sewage have been studied. Sepedonium n.sp., a predominating fungus, required organic sources of nitrogen while Fusarium aqueductum, Geotrichum sp., and Trichosporon cutaneum were able to utilize ammonium salts; F. aqueductum was also able to utilize nitrate. Geotrichum sp. and F. aqueductum needed no external supply of vitamins, $T$. cutaneum required thiamine and Sepedonium sp. required thiamine and biotin for optimum growth. The $\mathrm{pH}$ range for optimum growth was narrow ( $\mathrm{pH} 7$ to 8.5) for Sepedonium sp. while the ranges for the other fungi were much wider ( $\mathrm{pH} 3$ or 4 to 9 ).

$\mathrm{Zn}, \mathrm{Ca}, \mathrm{Mn}$ and probably $\mathrm{Fe}$ and $\mathrm{Cu}$ were required by Sepedonium sp., which was the only one of the four fungi inhibited by concentrations of $\mathrm{Zn}$ above the optimum in media partially deficient in other elements. $\mathrm{Mn}, \mathrm{Fe}$ or $\mathrm{Cu}$ when added with $\mathrm{Zn}$ counteracted the inhibitory action, while $\mathrm{Ca}$ increased it.

The purification of sewage by filtration through material such as gravel is due largely, if not solely, to the activity of organisms in the film present on the material of the filter. The film consists of algae, fungi and bacteria, together with amorphous matter derived from sewage. Excessive growth of the film, especially at the surface, may result in a decrease in the efficiency of the filter by impeding the percolation of sewage through the filter (causing 'ponding') and also by interfering with aeration. Fungi play an important part in causing ponding since the fibrous and intractable nature of the film is due largely to the presence of fungal mycelium (Tomlinson, 1942). Tomlinson \& Hall (1950) found that from 5 to $30 \%$ of the total solids in the film in eight small-scale filters was of fungal origin. Thus, if the growth of fungi were limited, the tendency of the filter to pond would be lessened while the efficiency of the process would probably not be impaired. For treating trade wastes unmixed with sewage, on the other hand, it may become desirable to promote the growth of fungi in order to purify the waste.

Little is known about the nutritional requirements of fungi encountered in sewage purification, and it was thought that such knowledge might be of use in the problem of fungus control. This paper describes experiments concerning the growth requirements of four sewage fungi. The effects on Sepedonium sp. of comparatively high concentrations of some trace elements are also described.

\section{METHODS}

Organisms. The fungi used were chosen because of their widespread occurrence in filters at many sewage works. Three of the organisms were identified by the Centraal Bureau at Baarn as Fusarium aqueductum Lagerh., Trichosporon 
cutaneum (de Beurm., Gougerot et Vaucher) and Geotrichum sp. (considered to be synonymous with Oospora). The fourth, which was isolated by Tomlinson (1942), was provisionally identified as a new species of Sepedonium by Dr Mason of the Commonwealth Mycological Institute.

Stock cultures were grown on glucose Yeastrel agar slopes and stored at room temperature. Except in the case of the new species of Sepedonium the inocula consisted of spores scraped with a platinum loop from the surface of cultures 1-2 weeks old. Sepedonium sp. was first subcultivated on $1 \%$ Bactoagar plates for 5-15 days, the inocula consisting of small pieces of agar containing a few hyphal fragments. Experiments have established that negligible carry-over of nutrients resulted from these methods of inoculation.

Composition of media. Medium A contained (g./l.): glucose (Difco) 5.0; vitamin-free Casamino acids (Difco), $5 \cdot 0 ; \mathrm{KH}_{2} \mathrm{PO}_{4}, 0.5 ; \mathrm{MgSO}_{4} .7 \mathrm{H}_{2} \mathrm{O}, 0.5$; $\mathrm{KCl}, \mathbf{0 \cdot 2 5}$. Water obtained by one distillation from a metal still was used.

Medium B was prepared by adding $2 \mathrm{ml}$. of solution $\mathrm{E}$ to every litre of medium A. Solution $\mathbf{E}$, based on a modification of Hoaglands ' $A$ to $\mathbf{Z}$ ' mixture (Robbins \& Kavanagh, 1938), was prepared by mixing separate solutions of salts of eleven trace elements immediately before use. The final concentrations of the elements in medium B were (in p.p.m.): $\left.\mathrm{Ca}\left(\mathrm{as}_{\mathrm{CaCl}}\right)_{2}\right) \mathbf{1} \cdot \mathbf{0}$; $\mathrm{Zn}\left(\right.$ as $\left.\mathrm{ZnSO}_{4}\right)$ 0.4; $\mathrm{Fe}\left(\right.$ as $\left.\mathrm{FeSO}_{4}\right) 0 \cdot 4 ; \mathrm{Cu}\left(\right.$ as $\left.\mathrm{CuSO}_{4}\right)$ 0.2; $\mathrm{Mn}\left(\right.$ as $\left.\mathrm{MnSO}_{4}\right)$ 0.2; $\mathrm{B}\left(\right.$ as $\left.\mathrm{H}_{3} \mathrm{BO}_{3}\right) 0 \cdot 2$; $\mathrm{Mo}\left(\right.$ as $\left.\left(\mathrm{NH}_{4}\right)_{6} \mathrm{Mo}_{2} \mathrm{O}_{7}\right) 0 \cdot 1 ; \mathrm{Ni}\left(\right.$ as $\left.\mathrm{NiCl}_{2}\right) 0 \cdot 1$; $\mathrm{Co}\left(\right.$ as $\left.\mathrm{Co}\left(\mathrm{NO}_{3}\right)_{2}\right)$ $0 \cdot 1 ; \mathrm{Br}($ as $\mathrm{KBr}$ ) $0 \cdot 1$; I (as $\mathrm{KI}) 0 \cdot 1$.

The media were adjusted, in most experiments, to $\mathrm{pH} 7$ with $\mathrm{NaOH}$; in some experiments adjustment to other $\mathrm{pH}$ values was made with $\mathrm{NaOH}$ or $\mathrm{H}_{2} \mathrm{SO}_{4}$.

A solid medium was prepared by mixing one part of quadruple-strength medium A, containing any substance being tested, and three parts of silica sol, prepared by the method of Taylor (1950), together with sufficient $\mathrm{NaOH}$ to neutralize the sterilized sol. The three components were sterilized separately by autoclaving at $15 \mathrm{lb}$./sq.in. for $15 \mathrm{~min}$. and were mixed immediately before pouring into Petri dishes.

The concentrations of vitamins used were $(\mu \mathrm{g} . / \mathrm{l}$.$) : biotin, 20; thiamine$ hydrochloride, pyridoxine hydrochloride, nicotinamide, folic acid, riboflavin, calcium pantothenate, $p$-aminobenzoic acid, 80 ; inositol, choline chloride, 1000. The liquid media were sterilized by autoclaving at $15 \mathrm{lb}$./sq.in. for $15 \mathrm{~min}$. after the addition of substances under test.

Removal of trace elements from media. It is well known that because of their powers of chelation it is difficult to free amino acids from trace elements. In preliminary experiments some measure of success was achieved in removing trace elements from medium $A$ by repeated extraction with 8-hydroxyquinoline (oxine) as described by Chesters \& Rolinson (1951). As Donald, Passey \& Swaby (1952) reported that a medium containing peptone could be at least partially purified by autoclaving with chromatographic $\mathrm{Al}_{2} \mathrm{O}_{3}$ (5 g./l.) at pH 7.5 (their method 5), this method was applied to medium $\mathbf{A}$. The other method used was no. 13, as listed by Donald et al. (1952), in which the medium was repeatedly extracted with oxine and then with dithizone. 
Conditions of cultivation. All glassware was cleaned in chromic + sulphuric acid mixture, thoroughly rinsed with tap water, then with distilled water and in appropriate cases, with double-distilled water. $100 \mathrm{ml}$. conical flasks (Hysil) containing $25 \mathrm{ml}$. medium were used. The flasks were fitted with cotton-wool plugs or with metal caps (Oxoid). All cultures were incubated in the dark at $20^{\circ}$ a temperature which Tomlinson (1942) had shown to be about optimum for the growth of Sepedonium sp. After incubation, for 10 days unless otherwise stated, the fungal mats were collected on sintered-glass crucibles (porosity no. 1), washed with distilled water, and dried for several hours at $100^{\circ}$. Filtration of cultures of Sepedonium sp. and $F$. aqueductum was rapid, but that of Geotrichum sp. and T. cutaneum was much slower. At least three flasks were used in each group and the means of the weights are recorded together with, in some cases, the standard deviations.

Serwage. Fresh settled sewage was filtered and, when necessary, its $\mathrm{pH}$ was adjusted to 7; its initial $\mathrm{pH}$ was usually $\mathbf{7 \cdot 5 - 8}$. It was then used without further treatment or was first concentrated tenfold in vacuo with a still temperature of about $60^{\circ}$.

Ashed sewage. Fresh settled sewage was filtered and the organic matter was destroyed either by evaporating to dryness and heating to redness after addition of $\mathrm{HNO}_{3}$ or by repeated evaporation with $\mathrm{HNO}_{3}$ on a steam bath. The residue in each case was dissolved in a little concentrated $\mathrm{HCl}$, with heating. The solution was then diluted to a convenient volume with distilled water and the $\mathrm{pH}$ value adjusted to 7 . A slight flocculent precipitate sometimes resulted and was dispersed by stirring immediately before the liquid was added to the culture medium. The two methods of destroying organic matter gave identical biological results.

\section{RESULTS}

\section{Growth rates}

The rates of growth of the four fungi were determined in medium B supplemented with vitamins. There was a lag period of 1-2 days except with Sepedonium sp., the lag period for which was 4 days. Maximum growth resulted after about 10 days with this fungus while the other fungi reached maximum growth after about 7 days.

\section{Effect of hydrogen ion concentration}

The relations between the initial $\mathrm{pH}$ value of the medium and growth of the four fungi are given in Fig. $1(a-d)$. Medium B supplemented with vitamins was used and the incubation period was 11 days, except for Sepedonium sp. which was incubated for 13 days. F. aqueductum and T. cutaneum were both capable of good growth over the wide $\mathrm{pH}$ range 4-9, and both tolerated $\mathrm{pH}$ values beyond this range. Geotrichum sp. also tolerated a wide range ( $\mathrm{pH} \mathrm{3-10)}$ and grew well over the range $\mathrm{pH} \mathrm{3-9;}$ best growth resulted at $\mathrm{pH} 3$ though no growth occurred at $\mathrm{pH} 2$. In contrast, Sepedonium sp. grew well only within narrow limits, $\mathrm{pH} 7-8 \cdot 5$, although it tolerated the $\mathrm{pH}$ range $4-10$. The $\mathrm{pH}$ values of those acid media in which 
growth had occurred had risen by varying degrees at the end of the incubation period while the $\mathrm{pH}$ values of alkaline media had fallen to about 8 .

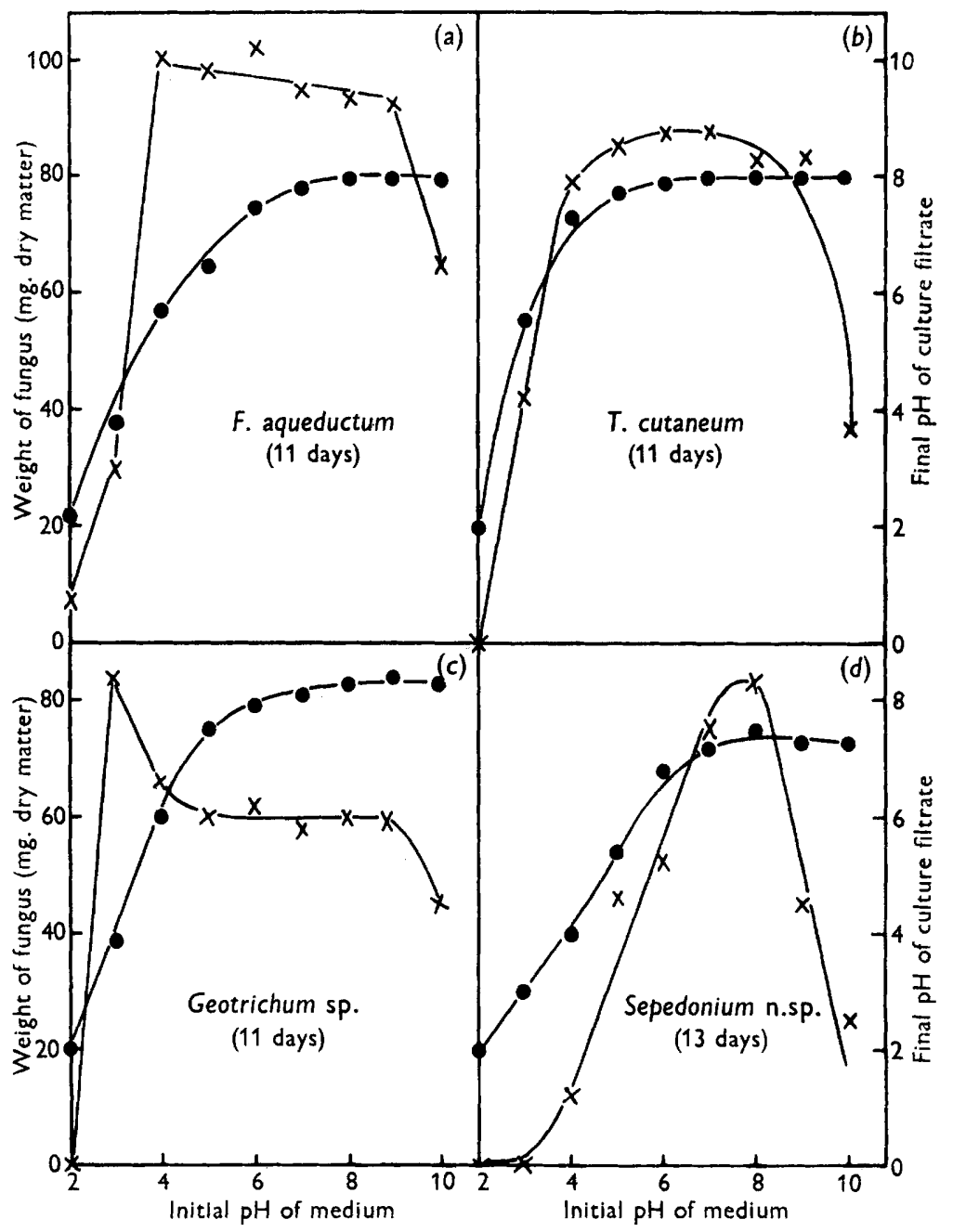

Fig. 1. Relation between pH value of medium and growth of fungus. Each point is the mean of four determinations. $-x-x-$, weight of fungus; --- , final $\mathrm{pH}$ value of medium.

The assimilation of various sources of nitrogen

The suitability of different sources of nitrogen for the four fungi was determined using medium $\mathbf{B}$, containing thiamine and biotin but omitting Casamino acids, as the basal medium. The various substances containing nitrogen were added in amounts such that each medium contained $0.035 \% \mathrm{~N}$ (equivalent to $0.5 \%$ vitamin-free Casamino acids). The yields of fungal mycelium are given in Table 1 which shows that Sepedonium sp. grew best on complex organic sources of nitrogen and grew very poorly when the nitrogen 
was provided by nitrate or ammonium sulphate, confirming the findings of Tomlinson (1942). Geotrichum sp. and T. cutaneum were able to utilize ammonium sulphate in addition to organic nitrogen, while $F$. aqueductum was able to utilize nitrate as well as the other forms of nitrogen. Best growth of all four fungi resulted when the source of nitrogen was Casamino acids. Other experiments in which Sepedonium sp. was cultivated on silica-gel media containing amino acids singly and in various combinations showed that the fungus did not preferentially utilize any of the eleven amino-acids tested; best growth resulted on the medium containing all eleven.

\section{Table 1. The availability of various sources of nitrogen to four fungi}

Nitrogen compounds added in amounts sufficient to give a concentration of $0.035 \% \mathrm{~N}$. Weight of Sepedonium n.sp. determined after 13 days; that of other fungi after 11 days. Each figure is the mean of four determinations.

Weight of fungus (mg. dry wt./25 ml. medium)

Source of nitrogen
None
$\mathrm{KNO}_{3}$
$\left(\mathrm{NH}_{4}\right)_{2} \mathrm{SO}_{4}$
Glycine
Asparagine
7 amino acids*
17 amino acids $\dagger$
'Casamino acids'
Bacto-peptone

F. aqueductum
4
48
35
59
64
-
96
99
66

T. cutaneum

2
3
55
54
50
59
68
83
52

52
Sepedonium

Geotrichum sp.

n.sp.

$\begin{array}{rr}2 & 5 \\ 1 & 7 \\ 38 & 12 \\ 19 & 12 \\ 22 & 41 \\ 33 & 42 \\ 32 & 40 \\ 53 & 73 \\ 24 & 68\end{array}$

* These were: glycine, cystine, glutamic acid, valine, leucine, proline and threonine.

$\dagger$ These were the above seven, together with ten others known to be constituents of casein.

\section{Vitamin requirements}

An indication of the vitamin requirements of the four fungi was first obtained by assessing visually their growth on medium B, solidified with silica gel, to which were added singly and in combinations ten members of the B-group vitamins. The results indicated that while $F$. aqueductum and Geotrichum sp. were independent of an external supply of vitamins, T. cutaneum required thiamine and Sepedonium sp. required some other factor or factors in addition to thiamine.

The requirements of the first three organisms were confirmed by results of experiments, given in Table 2, using liquid cultures with medium B as the basal medium. The growth of Geotrichum sp. and $F$. aqueductum, whether determined after 6 or 9 days, was not influenced appreciably by the vitamin content of the medium. T. cutaneum grew well only when thiamine was present while addition of other vitamins with thiamine did not further increase the yield. It can also be seen from Table 2 that Sepedonium sp. requires both thiamine and biotin. Thiamine alone resulted in poor growth while the presence of the other eight $\mathbf{B}$-vitamins in addition to thiamine and biotin produced no further increase in growth. 
Table 2. The influence of various B-group vitamins on the growth of four fungi

Weight of Sepedonium sp. determined after 12 days; that of other fungi after 6 days. Each weight given is the mean of three determinations. Standard deviations are given in brackets.

\section{Additions to vitamin- free medium}

None
Thiamine
Biotin
Pyridoxin
Thiamine + biotin
Thiamine + pyridoxin
Biotin + pyridoxin
9 members of B group
omitting thiamine
9 members of B group
+ thiamine

\begin{tabular}{cccc}
\multicolumn{4}{c}{ Weight of fungus (mg. dry wt./25 ml. medium) } \\
F. aqueductum & Geotrichum sp. & T. cutaneum & $\begin{array}{c}\text { Sepedonium } \\
\text { n.sp. }\end{array}$ \\
$87(4 \cdot 2)$ & $51(10)$ & $6(0 \cdot 7)$ & $10(1 \cdot 0)$ \\
$90(4 \cdot 0)$ & $53(5 \cdot 5)$ & $93(4 \cdot 0)$ & $18(1 \cdot 4)$ \\
$83(7 \cdot 2)$ & $60(5 \cdot 2)$ & $6(0 \cdot 7)$ & $13(6 \cdot 1)$ \\
$90(3 \cdot 5)$ & $62(3 \cdot 5)$ & $6(0 \cdot 7)$ & $12(2 \cdot 0)$ \\
$87(4 \cdot 1)$ & $61(4 \cdot 0)$ & $87(7 \cdot 2)$ & $74(3 \cdot 6)$ \\
$86(3 \cdot 2)$ & $64(4 \cdot 2)$ & $93(3 \cdot 1)$ & $18(2 \cdot 1)$ \\
$84(3 \cdot 7)$ & $50(2 \cdot 5)$ & $8(1 \cdot 6)$ & $17(2 \cdot 6)$ \\
$90(4 \cdot 0)$ & $59(5 \cdot 0)$ & $6(2 \cdot 0)$ & $21(3 \cdot 0)$ \\
$88(3 \cdot 7)$ & $65(6 \cdot 7)$ & $86(4 \cdot 1)$ & $71(2 \cdot 6)$
\end{tabular}

The concentration of thiamine which gave maximum growth of $T$. cutaneum and Sepedonium sp. under the conditions employed was $c .1 \mu \mathrm{g} . / 25 \mathrm{ml}$.; half maximum growth was produced by $c .0 \cdot 1 \mu \mathrm{g}$. $/ 25 \mathrm{ml}$. No inhibition resulted when the concentration was as high as $10 \mu \mathrm{g} . / 25 \mathrm{ml}$.

Two other types of Sepedonium, isolated from other filters, were found to have the same requirement as the original type. A fourth type, isolated from the River Dee, grew poorly on all media used.

Table 3. The requirement of Sepedonium sp. and $\mathbf{T}$. cutaneum for the moieties of thiamine

Each weight given is the mean of five determinations. Standard deviations are given in brackets.

\begin{tabular}{|c|c|c|}
\hline \multirow[b]{2}{*}{$\begin{array}{l}\text { Additions to biotin-supplemented } \\
\text { basal medium }\end{array}$} & \multicolumn{2}{|c|}{$\begin{array}{l}\text { Weight of fungus } \\
\text { (mg. dry wt./25 ml. medium) }\end{array}$} \\
\hline & $\begin{array}{l}\text { Sepedonium n.sp. } \\
\text { (after } 10 \text { days) }\end{array}$ & $\begin{array}{r}\text { T. cutaneum } \\
\text { (after } 7 \text { days) }\end{array}$ \\
\hline None & 14: $(2 \cdot 8)$ & $12(1 \cdot 7)$ \\
\hline Thiazole* & $12(1 \cdot 1)$ & $13(0 \cdot 5)$ \\
\hline Pyrimidine $\dagger$ & $16(5 \cdot 2)$ & $10(0.5)$ \\
\hline Thiazole + pyrimidine & $97(4.0)$ & $86(3 \cdot 0)$ \\
\hline Thiamine & $96(3 \cdot 5)$ & $85(4 \cdot 2)$ \\
\hline Sulphite-treated thiamine & $31(1 \cdot 2)$ & $49(4 \cdot 5)$ \\
\hline $\begin{array}{l}\text { Sulphite-treated } \\
\text { thiamine + thiamine }\end{array}$ & $95(5 \cdot 3)$ & $84(1 \cdot 3)$ \\
\hline
\end{tabular}

The results in Table 3 show that Sepedonium sp. and $T$. cutaneum require both the thiazole and pyrimidine moieties of the thiamine molecule for growth; neither moiety alone sufficed. A mixture of the two moieties was as good as thiamine itself when synthetic substances were used, but when thiamine hydrolysed by treatment with sulphite (Fitzgerald \& Hughes, 1949) 
was used, yields much less than the maxima were obtained. Thus the sulphite treatment (autoclaving at $10 \mathrm{lb}$./sq.in. for $10 \mathrm{~min}$. at $\mathrm{pH} \mathrm{5.4)}$ gave products which were not readily available to the fungi as sources of thiamine.

\section{Minor element requirements of Sepedonium sp.}

The requirements of Sepedonium sp. for trace elements were ascertained by determining the effects on growth of deficiencies of six elements in turn. The elements were added in concentrations probably somewhat above optimum to medium $\mathbf{A}$ which was supplemented with thiamine and biotin and which had been treated to remove trace elements. It was found that the trace elements were not removed to the same extent each time by either method used; Stockdale (1953) experienced similar, but greater, variations when she applied the $\mathrm{CaCO}_{3}$ method of Steinberg (1919) to a peptone medium. On some

\section{Table 4. Growth of Sepedonium n.sp. in medium treated by two methods to remove trace metals}

Complete medium contained $\mathrm{Fe}, \mathrm{Zn}, \mathrm{Cu}, \mathrm{Ca}, \mathrm{Mn}$, and $\mathrm{Mo}$. The elements were added at the following concentrations (p.p.m.): Fe, $\mathrm{Zn}, 2 ; \mathrm{Cu}, \mathrm{Mn}, 1 ; \mathrm{Ca}, 25 ; \mathrm{Mo}, 0.5$. Each weight is the mean of five determinations. Standard deviations are given in brackets.

\begin{tabular}{|c|c|c|c|c|c|c|c|c|}
\hline \multirow{3}{*}{$\begin{array}{l}\text { Treatment of } \\
\text { medium }\end{array}$} & \multirow{3}{*}{$\begin{array}{c}\text { Dry weight } \\
\text { of mycelium } \\
\text { in complete } \\
\text { medium } \\
\text { (mg. } / 25 \mathrm{ml} \text {. } \\
\text { medium) }\end{array}$} & \multicolumn{7}{|c|}{ Metal deficiency } \\
\hline & & All 6 & $\mathrm{Fe}$ & $\mathrm{Zn}$ & $\mathrm{Cu}$ & $\mathbf{C a}$ & $\mathbf{M n}$ & \\
\hline & & Weight o & fungus $i$ & deficier & media $(\%$ & f growth & comple & e medium) \\
\hline $\begin{array}{l}\text { Extraction with } \\
\text { oxine and } \\
\text { dithizone }\end{array}$ & $88(9 \cdot 8)$ & $14(8 \cdot 5)$ & $93(9 \cdot 3)$ & $57(10 \cdot 3)$ & $73(6 \cdot 0)$ & $27(12 \cdot 5)$ & $28(7 \cdot 1)$ & $97(15 \cdot 0)$ \\
\hline $\mathrm{Al}_{2} \mathrm{O}_{3}$ method & $91(2)$ & $1(0 \cdot 7)$ & $70(5 \cdot \tilde{5})$ & $52(9 \cdot 2)$ & $96(11 \cdot 5)$ & $14(8 \cdot 7)$ & $31(4 \cdot 0)$ & $95(4.5)$ \\
\hline
\end{tabular}

occasions in the present work the removal of trace elements as a whole was at least as good as that achieved by Donald et al. (1952) when they applied the $\mathrm{Al}_{2} \mathrm{O}_{3}$ method to $5 \%$ sucrose peptone water with Aspergillus niger as test organism.

From Table 4, which contains the results of experiments using each of the two methods described, it may be concluded that Sepedonium sp. requires $\mathrm{Zn}, \mathrm{Ca}$ and $\mathrm{Mn}$ and also probably $\mathrm{Fe}$ and $\mathrm{Cu}$; at no time was a requirement for Mo established. Except in the case of $\mathrm{Mn}$, the deficiencies of individual elements were not as complete as those obtained by the above authors. A probable reason for this is the comparative difficulty in removing the last traces of these metals from media (such as those used in the present work) containing amino acids, which were absent from the medium used in the studies of individual element requirements of $A$. niger (Donald et al. 1952). Each of the other fungi grew better when trace elements were added to the untreated medium; the requirements for individual elements were not determined. 


\section{Relation between concentration of minor elements and growth}

Some indication of the optimum concentration of trace elements was obtained by determining the yields of Sepedonium sp. in untreated medium A to which was added from 0 to $500 \mathrm{ml}$. solution $\mathrm{E} / \mathrm{l}$. The growth response was roughly logarithmic up to $50 \mathrm{ml}$. solution $\mathrm{E} / \mathrm{l}$. (Fig. 2). Growth was completely inhibited at $500 \mathrm{ml} . / \mathrm{l}$., which produced a fairly heavy precipitate in the medium. By extrapolation it was estimated that the particular batch of basal medium used produced the same effect as about $0.1 \mathrm{ml}$. solution $\mathrm{E} / \mathrm{l}$.

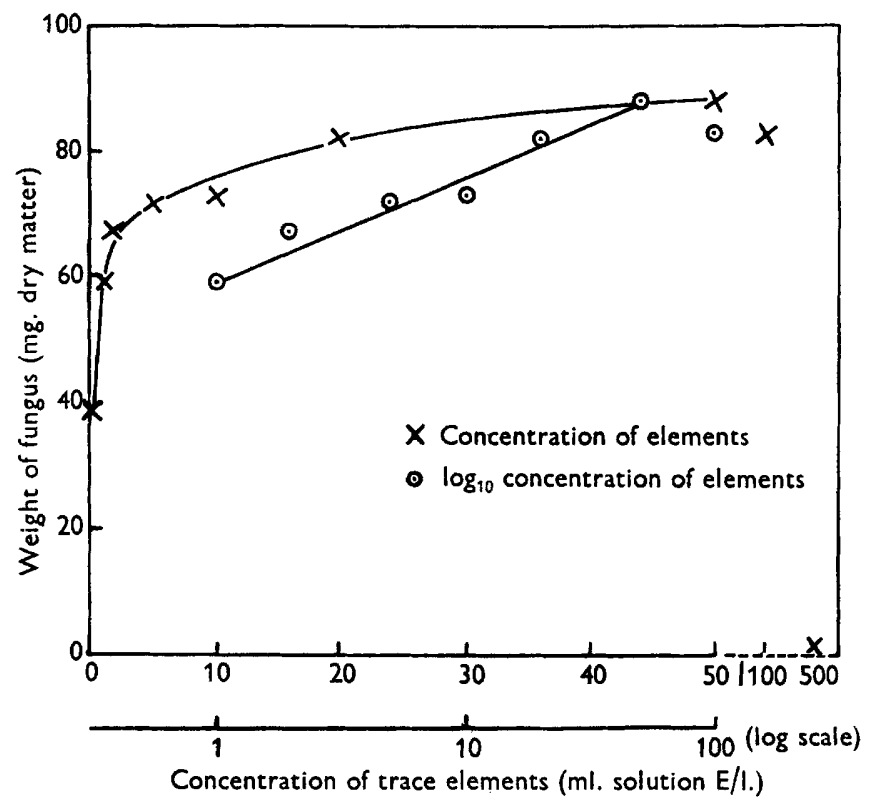

Fig. 2. Influence of the concentration of trace elements on the growth of Sepedonium n.sp. in untreated medium. $1 \mathrm{ml}$. solution E/l. gave the following concentrations (p.p.m.): $\mathrm{Ca}, 0.5 ; \mathrm{Fe}, \mathrm{Zn}, 0.2 ; \mathrm{Cu}, \mathrm{Mn}, 0 \cdot 1 ; \mathrm{Co}, \mathrm{Mo}, \mathrm{Ni}, \mathrm{Br}, \mathrm{I}, 0 \cdot 05$.

Since preliminary experiments showed that untreated medium $\mathbf{A}$ was apparently deficient only in $\mathrm{Zn}$ and $\mathrm{Ca}$ it was of interest to ascertain the effects on the growth of the fungus of various combinations of different concentrations of these two elements. Fig. 3 $(a)$ shows the growth response of Sepedonium sp. in vitamin-supplemented, untreated medium A to increasing concentrations of $\mathrm{Zn}$ under different conditions, namely: (i) with no further addition; (ii) with the addition of 10 p.p.m. Ca; (iii) with the addition of 10 p.p.m. Ca and nine other elements at concentrations equivalent to $20 \mathrm{ml}$. solution E/l. Fig. 3(b) shows the responses when the roles of $\mathrm{Zn}$ and Ca were reversed, 4 p.p.m. $\mathrm{Zn}$ being added in appropriate cases.

The results show that $\mathrm{Zn}$ was required at a concentration of 0.5-1.0 p.p.m., and $\mathrm{Ca}$ was required at the comparatively high concentration of 5-12.5 p.p.m. In the absence of other added elements, concentrations of $\mathrm{Zn}$ greater than the 
optimum inhibited growth; this inhibition was enhanced in the presence of 10 p.p.m. Ca. The addition of up to 25 p.p.m. Ca alone did not produce inhibition.

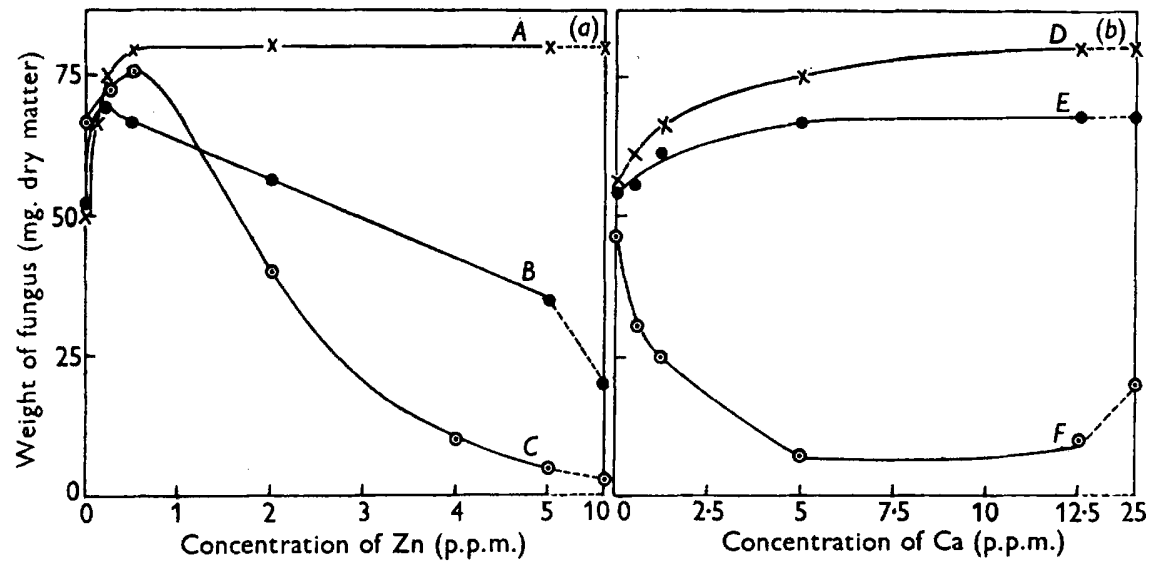

Fig. 3. Effect on the growth of Sepedonium n.sp. of high concentrations of $(a)$ zinc, and (b) calcium added to untreated medium. Elements added: $\mathrm{A}, \mathrm{Ca}$ and nine other elements at concentrations equivalent to the addition of $20 \mathrm{ml}$. of solution $\mathrm{E} / \mathrm{l}$.; $\mathrm{B}$, none; C, 10 p.p.m. Ca; D, $\mathrm{Zn}$ and nine other elements at concentrations equivalent to $20 \mathrm{ml}$. of solution $\mathrm{E} / \mathrm{l}$; ; E, none; F, 4 p.p.m. Zn.

\section{Effects of high concentrations of minor elements}

The effect of high concentrations of other elements was ascertained by adding them singly and in pairs to untreated medium $\mathbf{A}$ at the following concentrations (p.p.m.): $\mathrm{Fe}, \mathrm{Cu}, \mathrm{Mn}, \mathrm{Zn}, 10 ; \mathrm{Mo}, 5 ; \mathrm{Ca}, 25$. The results (Table 5) show that complex relations exist between the metals. $\mathrm{Zn}$ and Fe may be regarded as primary agents in causing inhibition under these conditions since only these two metals, when added singly, resulted in yields lower

Table 5. Effect on the growth of Sepedonium n.sp. of the addition to untreated medium of six metals, singly and in pairs, in relatively high concentrations

Each weight given is the mean of three determinations. Standard deviations are given in brackets. The metals were added at the following concentrations (p.p.m.): Mo, 5; $\mathrm{Zn}, \mathrm{Fe}, \mathrm{Cu}$, $\mathrm{Mn}, 10 ; \mathrm{Ca}, 25$.

Element added

$\overbrace{\mathrm{Zn}}^{\mathrm{Ca}} \mathrm{Fe} \quad \mathrm{Cu} \quad \mathrm{Mn} \quad \mathrm{Mo}$

\begin{tabular}{ccccccc}
$\begin{array}{c}\text { Element } \\
\text { added }\end{array}$ & \multicolumn{6}{c}{ Weight of fungus (mg. dry wt./25 ml. medium) } \\
Zn & $3(3 \cdot 1)$ & $1(0 \cdot 7)$ & $57(17 \cdot 0)$ & $79(12 \cdot 5)$ & $85(3 \cdot 6)$ & $39(16 \cdot 8)$ \\
$\mathrm{Ca}$ & - & $72(4 \cdot 1)$ & $46(3 \cdot 5)$ & $74(1 \cdot 7)$ & $74(1 \cdot 3)$ & $75(3 \cdot 1)$ \\
$\mathrm{Fe}$ & - & - & $26(3 \cdot 8)$ & $17(3 \cdot 1)$ & $47(3 \cdot 5)$ & $29(1 \cdot 7)$ \\
$\mathrm{Cu}$ & - & - & - & $45(0 \cdot 7)$ & $72(5 \cdot 0)$ & $58(7 \cdot 5)$ \\
$\mathrm{Mn}$ & - & - & - & - & $67(4 \cdot 0)$ & $71(1 \cdot 0)$ \\
$\mathrm{Mo}$ & - & - & - & - & - & $48(5 \cdot 3)$
\end{tabular}

Weight of fungus with no addition of metals $=45 \mathrm{mg}$. (4.0). Weight of fungus with addition of all six metals $=83 \mathrm{mg}$. (2.1). 
than the control (the yield in untreated medium containing no added trace elements but which contained trace elements as impurities). $\mathrm{Mn}$ and $\mathrm{Cu}$ completely prevented and Mo partially prevented the inhibition produced by $\mathrm{Zn}$, while in contrast the addition of $\mathrm{Ca}$ had no effect. The combination of $\mathrm{Zn}$ and $\mathrm{Fe}$ resulted in more growth than was produced by either element alone. The inhibition caused by $\mathrm{Fe}$, which was not so large as that caused by $\mathrm{Zn}$, was increased by the presence of $\mathrm{Cu}$, was unaltered by Mo, and was decreased by $\mathrm{Mn}$ and $\mathrm{Ca}$.

In other experiments in which the concentrations of the elements were smaller (namely (p.p.m.): $\mathrm{Fe}, \mathrm{Cu}, \mathrm{Mn}, \mathrm{Zn}, 4 ; \mathrm{Mo}, 2 ; \mathrm{Ca}, 10$ ) it was found that the only appreciable inhibition was produced by the combination of $\mathrm{Zn}$ and $\mathrm{Ca}$, either element alone having no inhibitory effect. It was also found that the growth-depressing effect of 10 p.p.m. $\mathrm{Zn}$ and 25 p.p.m. Ca could be completely overcome by the initial addition of as little as $2 \mathrm{ml}$. of solution $\mathrm{E} / \mathrm{l}$. Normal growth was also restored when the trace element solution was added to a 10-day-old inhibited culture. There was no similar inhibition of growth of the other fungi in the presence of 10 p.p.m. $\mathrm{Zn}$ and 25 p.p.m. Ca as was observed with Sepedonium sp.; $F$. aqueductum continued to grow well even at 100 p.p.m. Zn.

Cultures of Sepedonium sp. containing inhibitory concentrations of $\mathrm{Zn}$ and Ca not only grew feebly but also presented an appearance different from normal growth. Whereas the fungus normally grew in a continuous mat over the whole surface of the liquid, the $\mathbf{Z n}$-inhibited cultures grew in small submerged islets which were whiter and denser than normal growth. Microscopical examination revealed that $\mathrm{Zn}$ had induced a greater degree of hyphal branching and vacuolization (Pl. 1, fig. a). Cultures of the fungus inhibited by 10 p.p.m. Fe or 10 p.p.m. Fe and 10 p.p.m. $\mathrm{Cu}$ presented much the same appearance as normal cultures.

\section{Growth of Sepedonium sp. in the presence of sewage}

Little information is available concerning the presence of vitamins in settled sewage, although it is to be expected that, because of its origin, it would contain members of the $\mathbf{B}$ group unless they had been destroyed or otherwise removed during the passage of sewage through the sewers and through the primary sedimentation tanks at a disposal works. Rudolfs \& Heinemann (1940) showed that sewage contains substances which stimulate the growth of yeast, and Kraus (1942) established the presence of a factor in sewage which behaves like riboflavin. More recently Hoover, Jasewicz \& Porges (1951) demonstrated the presence of cobalamin in sewage sludge, and the presence of nicotinamide and pantothenic acid has also been reported ('H.J.S.' 1952).

A rough assessment of the thiamine content of sewage was made by determining the yields of Sepedonium sp. obtained in thiamine-free media to which were added varying amounts of sewage or concentrated sewage. Medium B, supplemented with biotin, was used as the control medium; the results are given in Table 6. Since it had been shown that $1 \mu \mathrm{g}$. thiamine $/ 25 \mathrm{ml}$. produced 
maximum growth and $100 \mathrm{ml}$. sewage $/ 25 \mathrm{ml}$. usually produced maximum growth, it may be inferred that the sewages tested contained thiamine in a concentration of the order of $1 \mu \mathrm{g} . / 100 \mathrm{ml}$. In other experiments in which biotin was omitted from the control medium the fungus grew well when sewage was added, indicating the presence of biotin in sewage.

Table 6. Growth of Sepedonium n.sp. in medium containing sewage as the sole source of thiamine

Volume of sewage present in $25 \mathrm{ml}$. medium (ml.)

$\overbrace{0}^{10}{ }_{50 *}{ }_{100 *}$

Weight of fungus (mg. dry wt./25 ml. medium)

Average of 6 means, each of

6

30

63

86 3 determinations

Range of means

$2-8 \quad 19-43$

35-80

$51-105$

* Added in the form of tenfold concentrated sewage.

To obtain some idea of the trace element content of sewage the yields of Sepedonium sp. were determined in medium A supplemented with thiamine and biotin and containing increasing amounts of sewage. Table $\boldsymbol{\gamma}$ shows that the smallest quantity of trace elements necessary for maximum growth was contained in 2-10 ml. sewage. When the experiment was repeated with re-dissolved ashed sewage (Table 7), maximum growth occurred in the same range of volume but the fungal yield was about $10 \%$ less than that obtained with whole sewage. This small difference, which was statistically significant at the $10 \mathrm{ml}$. level, occurred with all the samples of sewage tested, whether solely domestic or containing trade wastes.

Table 7. Influence of the amount and form of sewage on the growth of Sepedonium n.sp. in untreated medium containing the necessary vitamins but no added trace elements

Each weight given is the mean of six determinations. Standard deviations are given in brackets.

Volume of sewage present in $25 \mathrm{ml}$. medium (ml.)

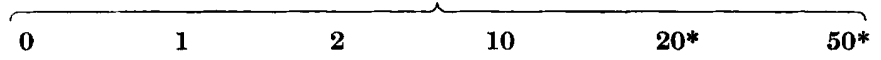

\begin{tabular}{lrlrrrr}
$\begin{array}{l}\text { Form of } \\
\text { sewage }\end{array}$ & \multicolumn{5}{c}{ Weight of fungus (mg. dry wt./25 ml. medium) } \\
Untreated & $48(7 \cdot 7)$ & $62(5 \cdot 4)$ & $80(7 \cdot 1)$ & $105(3.5)$ & $105(5 \cdot 2)$ & $105(4 \cdot 0)$ \\
Ashed & $48(7 \cdot 7)$ & $60(5 \cdot 5)$ & $76(4 \cdot 0)$ & $90(5 \cdot 5)$ & $90(4 \cdot 1)$ & -
\end{tabular}

* Added in the form of tenfold concentrated sewage.

This point was investigated in more detail by comparing the rates of growth of the fungus in a medium to which trace elements had been supplied by adding sewage $(10 \mathrm{ml} . / \mathrm{flask})$, ashed sewage ( $\equiv 10 \mathrm{ml}$. sewage/flask), or solution $\mathrm{E}(20 \mathrm{ml} . / \mathrm{l}$.). It can be seen from Fig. 4, which illustrates a typical set of results, that the growth curves obtained with solution $\mathrm{E}$ and with ashed 
sewage were identical within the limits of experimental error. The medium containing whole sewage produced a higher growth rate and a higher maximum yield (10-15\% higher) than either of the other two media. This small stimulatory effect could not be accounted for although a number of possible factors have been studied.

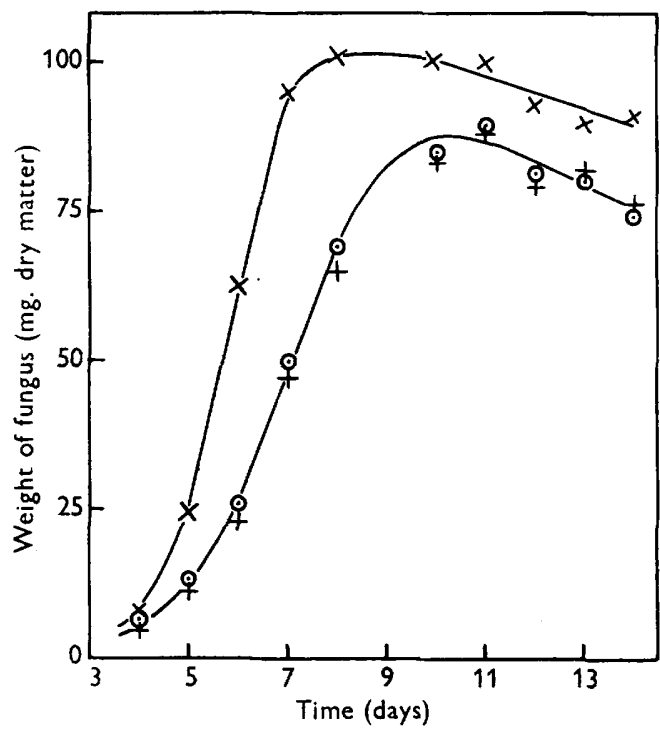

Fig. 4. The influence on the growth of Sepedonium n.sp. of sewage, ashed sewage, and trace elements added to untreated medium containing added vitamins. $-x-x, 10 \mathrm{ml}$. sewage $/ 25 \mathrm{ml}$. medium; - $\odot-\odot, 10 \mathrm{ml}$. sewage, ashed/25 ml. medium; - +- +, trace elements, $20 \mathrm{ml}$. solution $\mathrm{E} / \mathrm{l}$.

\section{DISCUSSION}

Whereas $\mathrm{Zn}, \mathrm{Mn}, \mathrm{Fe}$ and $\mathrm{Cu}$ shown here to be required (or probably required) by Sepedonium sp., have frequently been reported to be necessary for the growth of fungi, Ca has rarely been reported to be essential. Using very refined methods, Steinberg (1948) established that the growth of various fungi was inhibited to varying degrees in Ca-deficient media. In those cases where Ca was required (four or five out of seven), 2-6 p.p.m. gave optimum growth; this compares with 5-12.5 p.p.m. required by Sepedonium sp. More recently, Basu (1951) has shown that Ca stimulates the vegetative growth, as well as the fruiting, of some species of Chaetomium, the optimum concentration being in the region of 10 p.p.m. Taylor (1951) found that Ca stimulated the growth of certain soil bacteria, but was of opinion that it acted as an antagonist to some toxic substance in the peptone of his medium.

A point of interest arising from the results is that Sepedonium sp. is sensitive to comparatively low concentrations, 4-10 p.p.m., of Zn when grown in media partially deficient in other trace metals. True comparison with the results of other workers is difficult because of the differences in the trace element content of the basal media employed in the different investigations. Studies of this type have almost completely been confined to fungi which can 
utilize inorganic sources of nitrogen and consequently the media used have been more easily freed from trace elements than the media containing organic nitrogen used in the present work.

$\mathrm{Zn}$ has frequently been reported to be toxic to fungi, but usually the concentrations involved have been much higher than 4 p.p.m. For example, Gollmick (1936) found that 1000 p.p.m. Zn completely prevented the growth of Aspergillus niger in the presence of 1 p.p.m. Fe and 1 p.p.m. $\mathrm{Cu}$ while 500 p.p.m. Zn did not. Roberg (1928), however, claimed that as little as 1-5 p.p.m. Zn inhibited the growth of $A$. niger in the absence of $\mathrm{Fe}$, which when added with $\mathrm{Zn}$ removed the inhibition. This action was attributed by Roberg to antagonism but another explanation, put forward by Foster (1939), is that the organism required both $\mathrm{Zn}$ and $\mathrm{Fe}$. The latter view is supported by the fact that growth in the control medium containing no added metals was either the same as, or less than, that obtained when 1-5 p.p.m. Zn was added. In the case of Sepedonium sp. there seems to be an antagonistic action not only between $\mathrm{Zn}$ and $\mathrm{Fe}$ but also between $\mathrm{Zn}$ and $\mathrm{Mn}$ and between $\mathrm{Zn}$ and $\mathrm{Cu}$. This is thought to be so because the mycelial yield produced by the addition of 10 p.p.m. Zn was considerably less than that obtained with the partially deficient basal medium alone and because the addition of $\mathrm{Fe}, \mathrm{Mn}$, or $\mathrm{Cu}$ with $\mathrm{Zn}$ increased the yield to values greater than the control. It is to be pointed out that the growth of the fungus on the basal medium appeared to be normal and the yield, which was in the region of $50 \%$ of that obtained when the deficiencies were made good, was increased by the addition of $\mathrm{Zn}$ in concentrations up to about 2 p.p.m.

The effect of $\mathrm{Ca}$ also merits attention. While the addition of 4 p.p.m. $\mathrm{Zn}$ or 10 p.p.m. Ca to the basal medium did not result in any decrease in growth, the simultaneous addition of the elements at these concentrations lowered the yield almost to nothing. Mann (1932) observed a similar depressant effect by much higher concentrations of $\mathrm{Ca}$ on $\boldsymbol{A}$. niger, for which $\mathrm{Ca}$ is not essential. She found that 500 p.p.m. Ca lowered the yield produced by 0.65 p.p.m. $\mathrm{Zn}$ by $35 \%$ and 8000 p.p.m. lowered it by $46 \%$.

Increased branching of the hyphae and vacuolization in the hyphae caused by concentrations of Zn above optimal, as described here for Sepedonium sp., were observed by Iwanoff (1904) in $A$. niger and four other fungi. The concentrations used by this worker were considerably higher, namely $130-65,000$ p.p.m.

Finally, it may be mentioned that the differences in growth rates and nitrogen requirements between $\boldsymbol{F}$. aqueductum and Sepedonium sp. offer an explanation of the common observation that the former organism appears before the latter on the surface of percolating filters newly put into operation. This is supplementary to the explanation given by Tomlinson (1942) who showed that the undifferentiated thallus of Sepedonium sp., unlike that of $F$. aqueductum, is not adapted to adhere to a surface.

This paper is published by permission of the Department of Scientific and Industrial Research. Mr T. G. Tomlinson isolated the organisms, took the photographs and provided useful discussion and criticism. Miss D. H. M. Jordan and Mr R. A. Varley assisted with the experiments. 


\section{REFERENCES}

BASU, S. N. (1951). Significance of calcium in the fruiting of Chaetomium species, particularly Chaetomium globosum. J. gen. Microbiol. 5, 231.

Chesters, C. G. C. \& Rolinson, G. N. (1951). Zine in the metabolism of a strain of Aspergillus niger. J. gen. Microbiol. 5, 553.

Donald, C., Passey, B. I. \& Swaby, R. J. (1952). A comparison of methods for removing trace metals from microbiological media. J. gen, Microbiol. 7, 211.

Fitzgerald, E. E. \& Hughes, E. B. (1949). The microbiological assay of $B_{1}$. An improved method employing Lactobacillus fermenti 36. Analyst, 74, 340.

Foster, J. W. (1939). The heavy metal nutrition of fungi. Bot. Rev. 5, 207.

Golımick, F. (1936). Der Einfluss von Zink, Eisen und Kupfer und deren Kombination auf das Wachstum von Aspergillus niger. Zbl. Bakt. (2. Abt.), 93, 421.

'H.J.S.' (1952). From sewage, vitamins. Industr. Engng Chem. 44, no. 5, 13 A.

Hoover, S. R., JAsewicz, L. B. \& Porges, N. (1951). Vitamin $B_{12}$ in activated sewage sludge. Science, 114, 213.

IwANOFF, K. S. (1904). Ưber die Wirkung einiger Metallsalze und einatomiger Alkohole auf die Entwicklung von Schimmelpilzen. Zbl. Bakt. (2. Abt.), 13, 139.

Kraus, L. S. (1942). Riboflavin in sewage sludge. Servage Wks J. 14, 811.

Mann, M. L. (1932). Calcium and magnesium requirements of Aspergillus niger. Bull. Torrey bot. $\mathrm{Cl}$. 59, 443.

Robbins, W. J. \& Kavanagh, F. (1938). Vitamin $B_{1}$ or its intermediates and growth of certain fungi. Amer. J. Bot. 25, 229.

Roberg, M. (1928). Uber die Wirkung von Eisen-, Zink-, und Kupfersalzen auf Aspergillen. Zbl. Bakt. (2. Abt.), 74, 333.

Rudolfs, W. \& Heinemann, B. (1940). Growth-promoting substances in sewage and sludge. IV. Detection by biological agents. Servage Wks J. 12, 18.

Steinberg, R. A. (1919). A study of some factors in the chemical stimulation in the growth of Aspergillus niger. Amer. J. Bot. 6, 330.

Steinberg, R. A. (1948). Essentiality of calcium in the nutrition of fungi. Science, 107, 423.

Stockdale, P. M. (1953). Requirements for the growth and sporulation of Trichophyton persicolor. J. gen. Microbiol. 8, 434.

TaYlor, C. B. (1950). An improved method for the preparation of silica gel media for microbiological purposes. J. gen. Microbiol. 4, 235.

TAYlor, C. B. (1951). Nature of the factor in soil-extract responsible for bacterial growth-stimulation. Nature, Lond. 168, 115.

TomLinson, T. G. (1942). Some aspects of microbiology in the treatment of sewage. J. Soc. chem. Ind., Lond. 61, 53.

Tombinson, T. G. \& Hall, H. (1950). Some factors in the treatment of sewage in percolating filters. J. Inst. Sew. Purif. part 4, 338.

\section{EXPLANATION OF PLATE}

\section{Plate 1}

(a) Hyphae of Sepedonium n.sp. grown in vitamin-supplemented Medium A containing 4 p.p.m. Zn, 10 p.p.m. Ca and nine other elements at concentrations represented by 2 ml. solution E/l. $\times 200$.

(b) Hyphae of Sepedonium n.sp. grown in vitamin-suppleniented medium A containing 4 p.p.m. $\mathrm{Zn}+10$ p.p.m. Ca $\times 200$. 
Journal of General Microbiology, Vol. 10, No. 1
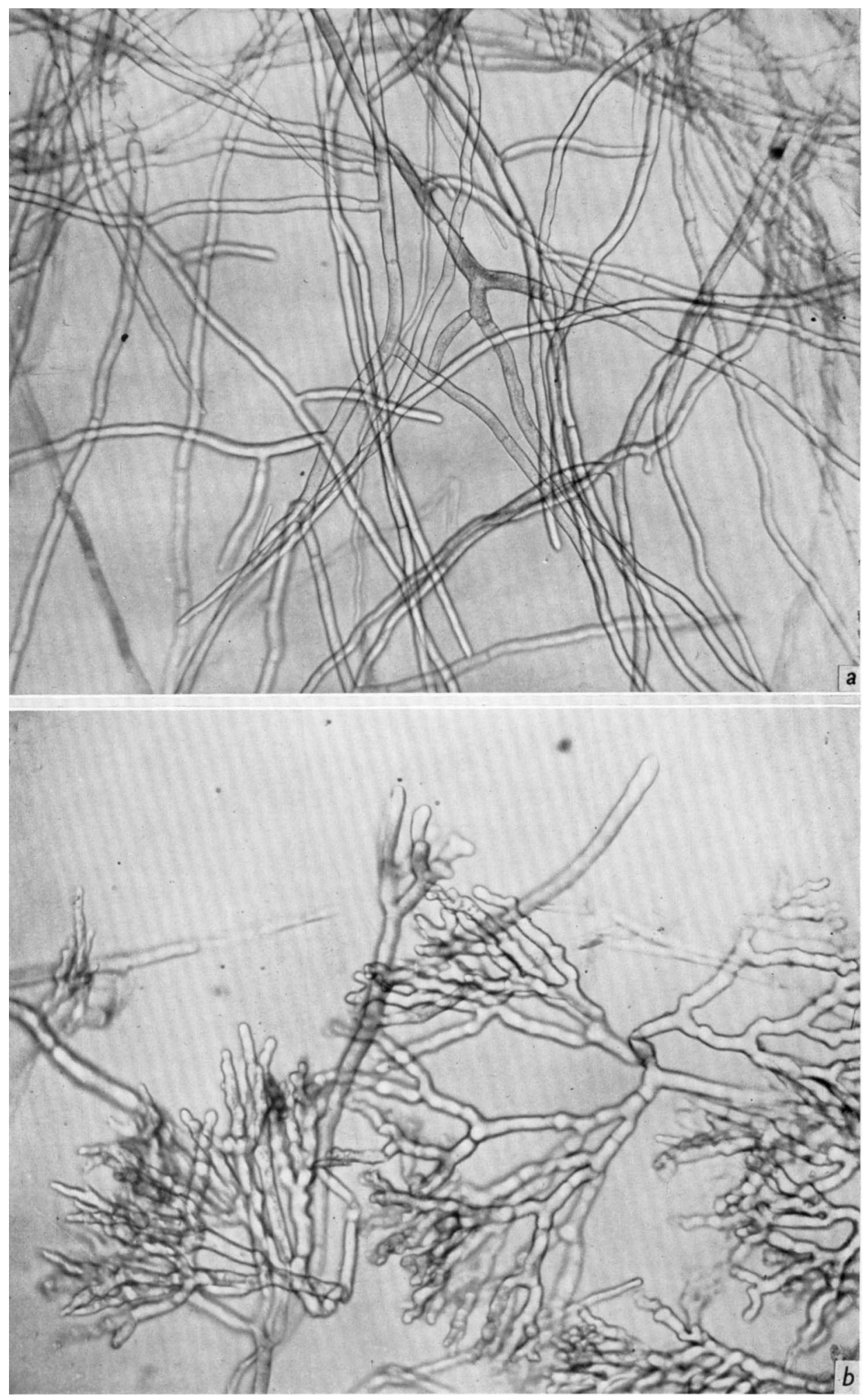

H. A. Painter-Factors affecting ghowth of sfwage rungi. Plate 1 